\title{
Prevalence of Undernutrition and Associated Factors among Pregnant Women in a Public General Hospital, Tigray, Northern Ethiopia: A Cross-Sectional Study Design
}

\author{
Ebud Ayele $\mathbb{D}^{1},{ }^{1}$ Guesh Gebreayezgi, ${ }^{1}$ Teklewoini Mariye $\mathbb{D}^{2},{ }^{2}$ Degena Bahrey, \\ Gebrekiros Aregawi, ${ }^{3}$ and Gebregziabher Kidanemariam ${ }^{3}$ \\ ${ }^{1}$ Department of Public Health Nutrition, College of Medicine and Health Sciences, Aksum University, Aksum, Ethiopia \\ ${ }^{2}$ Department of Nursing, College of Medicine and Health Science, Aksum University, Aksum, Ethiopia \\ ${ }^{3}$ Department of Midwifery, College of Medicine and Health Science, Aksum University, Aksum, Ethiopia \\ Correspondence should be addressed to Ebud Ayele; ebudayele@gmail.com
}

Received 2 June 2020; Revised 11 September 2020; Accepted 25 September 2020; Published 7 October 2020

Academic Editor: Luigi Schiavo

Copyright (C) 2020 Ebud Ayele et al. This is an open access article distributed under the Creative Commons Attribution License, which permits unrestricted use, distribution, and reproduction in any medium, provided the original work is properly cited.

Background. Undernutrition is a global health problem, particularly in pregnant women. Despite the limited studies performed in different parts of Ethiopia, the information about the prevalence of undernutrition of pregnant women in the current study area is not documented. Therefore, this study aimed to assess the prevalence of undernutrition and associated factors in pregnant women. Methods. An institution-based cross-sectional study design was conducted in the Tigray region from August 01 to December 30 , 2018. Study subjects were selected by systematic sampling technique from the respective hospitals. An interviewer-administered questionnaire was used to collect the data. Data were cleaned and entered using Epi-Data version 3.1 and then exported to statistical package for social science (SPSS) version 23.0 for analysis. Multivariate analyses were carried out, and adjusted odds ratios (AORs) with 95\% CI and significance level ( $p$ value) $<0.05$ were considered. Results. Out of the total 844 selected pregnant women, 840 participated in the study, yielding a response rate of $99.5 \%$; of this, respondent's undernutrition prevalence was found to be $40.6 \%$ with $95 \%$ confidence interval (38.93\% and $42.27 \%$ ). Agriculture as occupation (AOR $=2.6,95 \% \mathrm{CI}: 1.5,4.5)$, women who wanted the pregnancy $(\mathrm{AOR}=0.25,95 \% \mathrm{CI}: 0.14,0.448)$, no history malaria during pregnancy $(\mathrm{AOR}=0.291,95 \%$ : $(0.152$, $0.555)$ ), coffee intake during pregnancy $(\mathrm{AOR}=1.6,95 \% \mathrm{CI}: 1.04,2.69)$, and hemoglobin $<11 \mathrm{~g} / \mathrm{dl}(\mathrm{AOR}=4.9,95 \% \mathrm{CI}: 3.09,7.8)$ were the factors that were significantly associated with undernutrition, $p$ value $(<0.05)$. Conclusion. In this study, occupation, history of having malaria during pregnancy, wanted type pregnancy, coffee intake during pregnancy, and hemoglobin $<11 \mathrm{~g} / \mathrm{dl}$ were factors significantly associated with undernutrition in pregnant mothers. So, healthcare providers, policymakers, and other stakeholders should give special focus on these factors.

\section{Introduction}

Pregnancy strongly depends on the health and nutritional status of women, and a high proportion of pregnant women are affected by poor nutrition which leads them to unhealthy and distress conditions [1]. Optimal nutrition in mothers is not only crucial for their health but also for the health of future generations [2]. Undernutrition is among the most common causes of maternal mortality $[3,4]$.

Nutrition-related problems form the core of many current issues in women's health, and poor nutrition can have profound effects on reproductive outcomes [1]. $\mathrm{Nu}$ trition plays a vital role in reducing some of the health risks associated with pregnancy such as the risk of fetal and infant mortality, intrauterine growth retardation, low birthweight, premature births, decreased birth defects, cretinism, poor brain development, and risk of infection [5].

The global prevalence of undernutrition in mothers is about 462 million [6, 7]. And, this becomes the most important risk factor for morbidity and mortality, and hundreds of millions of pregnant women and young children are affected by undernutrition [8]. Undernutrition is a 
significant global health concern, particularly in pregnant women [9]. Adequate nutrition is essential for a woman throughout her life cycle, and pregnant women require varied diets and increased nutrient intake to cope with the extra needs during pregnancy. The use of dietary supplements and fortified foods should be encouraged for pregnant women to ensure an adequate supply of nutrients for both mother and fetus [5].

If adolescents or women are undernourished during pregnancy, the cycle of maternal malnutrition, fetal growth restriction, child stunting, subsequent lifetime of impaired productivity, and increased maternal and fetal morbidity and mortality are perpetuated [10]. Pregnancy is an anabolic process, and a woman's normal nutritional requirement increases during pregnancy to meet the needs of the growing fetus and the maternal tissues associated with pregnancy. Thus, the nutritional status of the expectant mother is one of the most important determinants affecting pregnancy outcomes [11].

Therefore, to address maternal undernutrition through intervention, a scientific study was of paramount importance to assess the present image of undernutrition and to identify factors that are affecting for undernutrition, and the available pieces of literature in Ethiopian were limited in addressing factories that influence undernutrition among pregnancy mothers. Therefore, this study aims to assess the prevalence and factors associated with undernutrition among pregnant women in a public general hospital of Tigray, Northern Ethiopia.

\section{Methods and Materials}

2.1. Study Design, Area, and Period. An institution-based cross-sectional study design was carried out. This study was conducted in public general hospitals of the Tigray region; in the region, there were 14 total public general hospitals from those five hospitals: Mekelle public general Hospital found in the regional administration, St. Marry public general hospital found in the central zone of the region, Lemlem Karl public general Hospital found in the southern zone of the region, Kahsay Abera public general Hospital west zone of the region, and Adigrat public general hospital found in the southeast were the selected study area. Data collection for this study was undertaken from August 01 to December 30, 2018.

2.2. Source and Study Population. The source populations were all third-trimester pregnant women who were coming for delivery and antenatal care visits in the selected public general hospitals of the Tigray region. Third-trimester pregnancy women who were coming for delivery and antenatal care visits in general public hospitals of the Tigray region were selected as the study population.

2.3. Inclusion and Exclusion Criteria. All selected third-trimester pregnant women who were coming for delivery and ANC in public general hospitals during the study period were included, whereas pregnancy women with bilateral edema were excluded.

2.4. Sample Size and Sampling Techniques. Sample size was calculated using single population proportion formula by assuming precision $(d)=5 \%$, confidence level $=95 \%$ $(\mathrm{Z} \alpha / 2=1.96)$, and proportion of undernutrition $(P)=50 \%$. By considering a $10 \%$ nonresponse rate, it becomes 422 . Finally, 844 pregnant women were taken as a final sample size after using the design effect two. Two-stage sampling was employed to select the study participants. In Tigray, there were 14 public general hospitals; from those, five hospitals were selected randomly and the sample size was proportionally allocated to each hospital. A systematic random sampling technique was used to select every (determined interval $K=2$ ) study subjects from all the five hospitals.

2.5. Data Collection Procedures. A semistructured questionnaire was initially prepared in English and then translated into the local language; Tigrigna was used. Tigrigna version was again translated back to English to check for any inconsistencies or distortion in the meaning of words. Data were collected using an interviewer-administered, and MUAC measurement questionnaire was adapted from the literature. Data collection was performed by five B.Sc. nurses. To assure the quality of the data properly designed data collection instrument and training of data collectors and supervisors was done, the enumerators and the supervisor were given training for three days on procedures, techniques, ways of collecting the data, and monitoring the procedure. Ten percent pretest was done at the Shul public general hospital to check the consistency of the questioner. The collected data were reviewed and checked for completeness by supervisors and principal investigators each week. MUAC was measured by considering the mothers in Frankfurt plane and sideways to measure the left side, arms hanging loosely at the side with the palm facing inward, taken at marked midpoint of upper left arm, a flexible nonstretchable tape should be used, and difference between trainee and trainer should be $0-5 \mathrm{~mm}$.

2.6. Independent and Dependent Variables. Nutritional status of pregnant mothers is the outcome variable, and the independent variables were all the sociodemographic characteristics and maternal obstetrical and gynecology history. A brief description of how some of these variables were measured is as follows.

2.7. Dependent Variable. The mid-upper arm circumstance values below a cutoff point $<23 \mathrm{~cm}$ were considered as undernutrition in this study, whereas for the individual in the third-trimester $(23 \mathrm{~cm}$ and above), it was considered normal [12].

2.8. Potential Confounding Factors. Potential confounding variables measured in the study were sociodemographic characteristics and obstetrics and gynecology including the 
age of mother, marital status, religion, educational background of mothers and household, income, occupation, ethnicity, number of antenatal care visits, type of pregnancy, maternal previous surgery, malaria, parity, iron and folic acid supplementation, marriage at age, hemoglobin level, coffee intake, husband's support, depression, difficulty to access food during the last three months, and history of low birthweight.

2.9. Anthropometric Measurement. The anthropometric measurement midupper arm circumstance was taken from individual third-trimester pregnant women.

2.10. Data Management and Analyses. After data were entered into Epi-Data 3.1, they were exported to (SPSS) Version 23 for analysis. Binary logistic regression analysis was executed to see the association between independent and outcome variables. All explanatory variables associated with the outcome variable with $p<0.25$ were entered into multivariable logistic regression analysis, and a significant association was identified based on $p<0.05$ and AOR with 95\% CI.

\section{Results}

3.1. Socioeconomic and Demographic Characteristics of Pregnant Women. A total of 840 pregnant women were included in the study with a response rate of $99.5 \%$. The mean age of the pregnant women was $36(S D+1.3)$ years. About 747 (88.9\%) pregnant women were married, 322 (38\%) of them were pregnant doing agriculture, 280 (33.3\%) of mothers were aged from 30 to 34 years, about $772(91.9 \%)$ of the pregnant women were of Tigray ethnicity, and $794(71.2 \%)$ were orthodox in religion. Out of 747 married mothers, $268(31 \%)$ of their husbands had a high school degree, 322 (38.3\%) pregnant women were of elementary school, and $280(33.3 \%)$ pregnancy women had a monthly income less than 1000 Ethiopian Birr (Table 1).

3.2. Health and Health Care Service Characteristics of Pregnant Women. Out of 840 participating in the study yielding to a response rate of $99.5 \%$, undernutrition was found in $40.6 \%$. About 606 (78.8\%) had two-time antenatal care visit, $435(51.7 \%)$ out of pregnant women had wanted type pregnancy, 732 (5178\%) had no history of previous surgery, $771(91.78 \%)$ had no history malaria during pregnancy, 596 (70.95\%7) had no history of low birthweight, 435 (51.78\%) pregnant women had multiple $\geq 5$ children, labout 710 $(84.5 \%)$ pregnant women were in iron and folic acid supplementation during the current pregnancy, 652 (77.6\%) pregnant women were married at the age $>18$ year, 590 (70.2\%) pregnant women had a hemoglobin level $>11 \mathrm{~g} / \mathrm{dl}$, $560(66.6 \%)$ women were daily coffee drinkers, 450 (53.5\%) women's husbands were supported them during the current pregnancy, about $650(77.38 \%)$ women had no history of depression, and 598 (71.19\%) had difficulty to access food in the last three months (Table 2).
TABle 1: Socioeconomic and demographic characteristics of pregnant women in public general hospitals of Tigray Ethiopia 2018 $(n=840)$.

\begin{tabular}{|c|c|c|c|}
\hline Variable & Category & Frequency & Percent \\
\hline \multirow{2}{*}{ Marital status } & Divorced & 93 & 11.07 \\
\hline & Married & 747 & 88.9 \\
\hline \multirow{5}{*}{ Occupation } & Housewife & 142 & 16.9 \\
\hline & Agriculture & 322 & 38.3 \\
\hline & Government employee & 268 & 31.9 \\
\hline & $\begin{array}{c}\text { Nongovernment } \\
\text { employee }\end{array}$ & 110 & 13.09 \\
\hline & Housewife & 142 & 16.9 \\
\hline \multirow{2}{*}{ Religion } & Orthodox & 794 & 94.5 \\
\hline & Muslim & 46 & 5.47 \\
\hline \multirow{7}{*}{ Mother's age } & $15-19$ & 48 & 5.7 \\
\hline & $20-24$ & 36 & 4.28 \\
\hline & $25-29$ & 42 & 5 \\
\hline & $30-34$ & 280 & 33.3 \\
\hline & $35-39$ & 223 & 26.5 \\
\hline & $40-44$ & 154 & 18.3 \\
\hline & $45-49$ & 57 & 6.78 \\
\hline \multirow{5}{*}{$\begin{array}{l}\text { Husband's } \\
\text { education }\end{array}$} & No education & 167 & 19.88 \\
\hline & Elementary & 231 & 27.5 \\
\hline & High school & 268 & 31.9 \\
\hline & Preparatory school & 58 & 6.9 \\
\hline & College and above & 116 & 13.8 \\
\hline \multirow{2}{*}{ Ethnicity } & Tigray & 772 & 91.9 \\
\hline & Others & 68 & 8 \\
\hline \multirow{4}{*}{ Mother's education } & No education & 142 & 16.9 \\
\hline & Elementary & 322 & 38.3 \\
\hline & High school & 268 & 31.9 \\
\hline & College and above & 108 & 12.8 \\
\hline \multirow{4}{*}{$\begin{array}{l}\text { Income (Ethiopian } \\
\text { Birr) }\end{array}$} & Less then 1000 & 280 & 33.3 \\
\hline & 1001-2000 & 225 & 26.78 \\
\hline & $2001-3000$ & 246 & 29.2 \\
\hline & Above 3001 & 89 & 10.59 \\
\hline
\end{tabular}

3.3. Results of Logistic Regression Analysis. The bivariate analysis showed that malaria, maternal educational status, type of pregnancy, coffee intake, history of low birthweight, hemoglobin, iron and folic acid supplementation, occupation, age of mothers, income, age during marriage, type of pregnancy, and difficulty in food supplementation were crudely associated with $25 \%$ level of significance.

Variables associated with adjusted analysis: pregnant women whose occupation is agriculture were more likely $[\mathrm{AOR}=2.6,95 \% \mathrm{CI}: 1.5,4.5]$ to have undernutrition than their counterpart, women who had wanted type pregnancy were less likely $[\mathrm{AOR}=0.25,95 \% \mathrm{CI}: 0.14,0.448]$ to be undernutritioned than that of planned-pregnancy women; mothers with no malaria infection during pregnancy were less likely $[\mathrm{AOR}=0.291,95 \%$ : $(0.152,0.555)]$ to become undernutritioned than their counterpart; mothers who were coffee drinkers were more likely $[\mathrm{AOR}=1.6,95 \% \mathrm{CI}$ : 1.04, 2.69 ] to be undernutritioned than their counterpart; mothers with hemoglobin $<11 \mathrm{~g} / \mathrm{dl}$ were more likely $[\mathrm{AOR}=4.9,95 \%$ CI: $3.09,7.8$ ] to be undernutritioned than their counterpart (Table 3). 
TABLE 2: Frequency distribution of health and health-related variables among pregnant women in public general hospitals of Tigray, Ethiopia $2018(n=840)$.

\begin{tabular}{|c|c|c|c|}
\hline Variable & Category & Frequency & Percent \\
\hline \multirow{3}{*}{ Type of pregnancy } & Unwanted & 159 & 18.9 \\
\hline & Unplanned & 146 & 17.38 \\
\hline & Wanted & 435 & 51.78 \\
\hline \multirow{2}{*}{ Maternal previous surgery } & Yes & 37 & 4.8 \\
\hline & No & 732 & 95.2 \\
\hline \multirow{2}{*}{ Malaria } & Yes & 69 & 8.2 \\
\hline & No & 771 & 91.78 \\
\hline \multirow{3}{*}{ How many ANCs? } & One & 25 & 3.3 \\
\hline & Two & 606 & 78.8 \\
\hline & Three and above & 138 & 17.9 \\
\hline \multirow{2}{*}{ Coffee intake } & Yes & 676 & 80.4 \\
\hline & No & 164 & 19.5 \\
\hline \multirow{2}{*}{ History of low birthweight } & Yes & 245 & 29.16 \\
\hline & No & 596 & 70.95 \\
\hline \multirow{3}{*}{ Parity } & Primipara & 159 & 18.9 \\
\hline & 2-4 children & 246 & 29.28 \\
\hline & Multiple $\geq 5$ & 435 & 51.78 \\
\hline \multirow{2}{*}{ Iron and folic acid supplementation } & Yes & 710 & 84.5 \\
\hline & No & 130 & 15.47 \\
\hline \multirow{2}{*}{ Age at marriage } & $<18$ year & 188 & 22.38 \\
\hline & $>18$ year & 652 & 77.6 \\
\hline \multirow{2}{*}{ Hemoglobin $<11 \mathrm{~g} / \mathrm{dl}$} & Yes & 250 & 29.76 \\
\hline & No & 590 & 70.2 \\
\hline \multirow{2}{*}{$\mathrm{MUAC}<23 \mathrm{~cm}$} & $>23 \mathrm{~cm}$ & 499 & 59.4 \\
\hline & $<23 \mathrm{~cm}$ & 341 & 40.59 \\
\hline \multirow{3}{*}{ Husband's support } & Always & 450 & 53.57 \\
\hline & Sometimes & 152 & 18.09 \\
\hline & Never & 238 & 28.3 \\
\hline \multirow{2}{*}{ Depression } & Yes & 90 & 10.7 \\
\hline & No & 650 & 77.38 \\
\hline \multirow{2}{*}{ Difficulty to access food in the last three months } & Yes & 142 & 16.9 \\
\hline & No & 598 & 71.19 \\
\hline
\end{tabular}

\section{Discussion}

In this study finding, the magnitude of undernutrition in pregnant women was $40.6 \%$ with $95 \%$ CI $(38.93 \%$ and $42.27 \%$ ), which is higher than that in the study conducted in Alamata (22.3\%), Bangladesh (23.5\%) [13], Amhara Gonder (14.4\%) [14], eastern Ethiopia (23.3\%) [15], southern Ethiopia (20.9\%) [16], Sri Lanka [17], and southern Ethiopia (31.4\%) with MUAC $<22$ [18] of the participated pregnant women who were undernutritioned. This discrepancy may be because of the study setting and the cutoff point that was used between the studies and the term of the study participants. However, this study was almost similar to the study performed in Oromia Region (38.3\%) [19]. Whereas compared with our finding, a lower prevalence of undernutrition was reported in Alta Choko, southern Ethiopia (71.1\%) [20] and Ardal country (51.3\%) [21]. This may be due to the MUAC cutoff point $<19-22 \mathrm{~cm}$ that they used, sample size difference, and sociodemographic difference.

Mothers whose occupation is agriculture were 2.6 times more likely $[\mathrm{AOR}=2.6,95 \% \mathrm{CI}: 1.5,4.5]$ to have undernutrition than those who are housewives. This study is similar to the study performed in pregnant women living in Bangladesh doing agriculture who were more undernutritioned and to the other studies which were conducted in Ethiopia [13, 16, 22]. This is because mothers in lowincome countries are spending their time to do agriculture than caring for themselves, and the working intensity might also be hard for pregnant women.

In this study, mothers with wanted type pregnancy were $75 \%$ less likely $[\mathrm{AOR}=0.25,95 \% \mathrm{CI}: 0.14,0.448$ ] to became undernutritioned than those with unwanted pregnancy. This finding is similar to the evidence from low- and middleincome countries which indicated that unwanted pregnancy can affect maternal nutrition, health service, and child nutrition $[23,24]$. This is because mothers with wanted pregnancy type have planned programs on how to feed themselves and prepare to have diversified food types in their homes.

Pregnancy mothers with no malaria during pregnancy were $70.09 \%$ less likely $[\mathrm{AOR}=0.291,95 \%$ : $(0.152,0.555)]$ to become undernutritioned than those having malaria during 
TABLE 3: Factors associated with undernutrition in pregnant women in public general hospitals of northern Ethiopia $2018(n=840)$.

\begin{tabular}{|c|c|c|c|c|c|}
\hline \multirow{2}{*}{ Variables } & \multirow{2}{*}{ Category } & \multicolumn{2}{|c|}{ Instrument } & \multirow{2}{*}{ COR 95\% CI } & \multirow{2}{*}{ AOR 95\% CI } \\
\hline & & Yes & No & & \\
\hline \multirow{2}{*}{$\begin{array}{l}\text { Difficulty in food supplementation } \\
\text { during the last } 3 \text { months }\end{array}$} & No & 469 & 303 & $0.510(0.309,0.841)$ & $0.716(0.374,1.369)$ \\
\hline & Yes & 30 & 38 & 1 & 1 \\
\hline \multirow{7}{*}{ Age of the mother } & $15-19$ & 28 & 20 & 1 & 1 \\
\hline & $20-24$ & 24 & 12 & $0.700(0.285,1.721)$ & $0.774(0.239,2.504)$ \\
\hline & $25-29$ & 26 & 16 & $0.862(0.369,2.009)$ & $1.798(0.596,5.426)$ \\
\hline & $30-34$ & 178 & 102 & $0.802(0.430,1.496)$ & $1.219(0.514,2.891)$ \\
\hline & $35-39$ & 111 & 112 & $1.413(0.752,2.655)$ & $2.093(0.857,5.109)$ \\
\hline & $40-44$ & 102 & 52 & $0.714(0.367,1.386)$ & $1.260(0.510,3.114)$ \\
\hline & $45-49$ & 30 & 27 & $1.260(0.581,2.733)$ & $1.497(0.516,4.34)$ \\
\hline \multirow{4}{*}{ Occupation } & Housewife & 89 & 53 & 1 & 1 \\
\hline & Agriculture & 166 & 156 & $1.578(1.053,2.364)$ & $2.643(1.548,4.513)^{* *}$ \\
\hline & Government employee & 180 & 88 & $0.821(0.537,1.256)$ & $1.576(0.848,2.927)$ \\
\hline & Nongovernment employee & 64 & 44 & $1.154(0.691,1.928)$ & $2.295(0.971,5.42)$ \\
\hline \multirow{3}{*}{ Type of pregnancy } & Unwanted & 36 & 123 & 1 & 1 \\
\hline & Planned & 115 & 131 & $0.333(0.213,0.522)$ & $0.777(0.447,1.350)$ \\
\hline & Wanted & 348 & 87 & $0.073(0.047,0.114)$ & $0.253(0.143,0.448)^{* *}$ \\
\hline \multirow{5}{*}{ Mother's educational status } & No education & 140 & 27 & $0.396(0.225,0.697)$ & $0.617(0.319,1.193)$ \\
\hline & Elementary & 153 & 78 & $1.046(0.651,1.681)$ & $0.988(0.558,1.74)$ \\
\hline & High school & 103 & 165 & $3.288(2.077,5.205)$ & $1.649(0.941,2.89)$ \\
\hline & Preparatory school & 25 & 33 & $2.709(1.417,5.182)$ & $1.048(0.452,2.427)$ \\
\hline & College and above & 78 & 38 & 1 & 1 \\
\hline \multirow{2}{*}{ Malaria status } & No & 479 & 292 & $0.249(0.145,0.427)$ & $0.291(0.152,0.555)^{* *}$ \\
\hline & Yes & 20 & 49 & 1 & 1 \\
\hline \multirow{2}{*}{ Coffee intake } & Yes & 398 & 278 & $1.120(0.789,1.589)$ & $1.678(1.046,2.690)^{*}$ \\
\hline & No & 101 & 63 & 1 & 1 \\
\hline \multirow{2}{*}{$\begin{array}{l}\text { History of low birthweight } \\
\text { and preterm }\end{array}$} & Yes & 148 & 97 & $0.943(0.696,1.277)$ & $1.146(0.643,2.043)$ \\
\hline & No & 351 & 244 & 1 & 1 \\
\hline \multirow{2}{*}{ Age at marriage } & $<18$ years & 144 & 44 & $0.365(0.252,0.529)$ & $0.685(0.383,1.226)$ \\
\hline & $>18$ years & 355 & 297 & 1 & 1 \\
\hline \multirow{2}{*}{ Hemoglobin $<11$ g/dl } & Yes & 59 & 191 & $9.496(6.720,13.4)$ & $4.943(3.097,7.888)^{* *}$ \\
\hline & No & 440 & 150 & 1 & 1 \\
\hline \multirow{2}{*}{ Iron and folic acid supplementation } & Yes & 398 & 312 & $2.730(1.761,4.2)$ & $1.202(0.613,2.36)$ \\
\hline & No & 101 & 29 & 1 & 1 \\
\hline \multirow{4}{*}{ Income } & Less than 1000 & 190 & 90 & 1 & 1 \\
\hline & $1001-2000$ & 129 & 96 & $1.571(1.091,2.261)$ & $1.344(0.842,2.146)$ \\
\hline & $2001-3000$ & 137 & 109 & $1.680(1.177,2.396)$ & $1.288(0.821,2.022)$ \\
\hline & Above 3001 & 43 & 46 & $2.258(1.39,3.6)$ & $1.126(0.582,2.18)$ \\
\hline
\end{tabular}

${ }^{* *} p \leq 0.001 ;{ }^{*} p<0.05$.

pregnancy. This finding was similar to that of the study performed in Nigeria, in which it was found that malaria can cause anemia, another study performed in Alamata Tigray, a study performed in Amazonian Region [14, 16, 25-27], and others. This is because malaria is one of the proximal factors that cause undernutrition in pregnancy.

Mothers consuming coffee was 1.6 times more likely $[\mathrm{AOR}=1.6,95 \% \mathrm{CI}: 1.04,2.69]$ to be undernutritioned than those in the counterpart. This finding was similar to that of the study performed in Costa Rica, Ethiopia, and also that of other studies [28-30]. This because coffee intake affects iron bioavailability, and due to its potency as an inhibitor of absorption, it is likely to aggravate anemia at times of increased physiological need or when dietary iron intake is precarious and can compete with other nutrients [31]. Drinking coffee can cause nutrient depletion of important nutrients, such as vitamin B6, and interfere with nutrient absorption of essential minerals, including calcium, iron, magnesium, and vitamin B.

Mothers with hemoglobin $<11 \mathrm{~g} / \mathrm{dl}$ were 4.9 times more likely $[\mathrm{AOR}=4.9,95 \% \mathrm{CI}: 3.09,7.8]$ to have undernutrition than their counterparts. This finding was similar to that of the study performed in Wonde Genetin, southern Ethiopia, Nigeria and study done in Reft valley $[4,25,26,32,33]$. Women who were anemic were also more likely to have a low MUAC. A study demonstrated that an MUAC measurement above $23 \mathrm{~cm}$ reduced odds of anemia by 0.41 .

\section{Conclusion and Recommendation}

Above one-third of pregnant mothers were undernutritioned in this study, it was found to be higher than that 
in other similar studies; it should be considered as a major public health problem in this study area. Our study also identified malaria during pregnancy, occupation, coffee intake, hemoglobin level, and type of pregnancy were factors associated with pregnant mothers' undernutrition, so healthcare providers and health organizations should give special focuses on these factors. Multisectoral collaboration and coordination between national and international organizations will also be needed for prevention. Counseling services for pregnant mothers might also help to improve their nutritional status. The mothers shall also be counseled about the effect of frequent coffee consumption to their fetus and their health.

5.1. Limitation of This Study. The cross-sectional nature of the study might affect the establishment of a causal relationship between identified risk factors and undernutrition; this study is an institution-based study, and other health services were not included. This study failed to incorporate the dietary diversity score as a risk factor of undernutrition which might have also introduced a residual confounding problem.

\section{Abbreviations}

ANC: Antenatal care

AOR: Adjusted odds ratio

CI: Confidence interval

COR: Crude odds ratio

CS: $\quad$ Caesarean section

$\mathrm{cm}$ : Centimeters

MUAC: Mid-upper arm circumference.

\section{Data Availability}

The complete dataset used and/or analyzed during the current study are available from the corresponding author and can be accessed upon reasonable request.

\section{Ethical Approval}

Before starting the data collection process, ethical clearance was given by the Aksum University Health Bureau's Ethical Clearance Committee to each selected hospitals.

\section{Consent}

Informed, written, and signed consent was obtained from each participating pregnant women after the purpose and benefits of the study are discussed and from each head of every facility involved in the study. Participants were informed about the minimal risk that it had been there in the study, their volunteerism, and right to leave the interview at any time they want. Confidentiality of the study participant's information was also kept secured.

\section{Conflicts of Interest}

The authors declare that they have no conflicts of interest.

\section{Authors' Contributions}

EA conceived and designed the study, analyzed the data, and wrote the manuscript. GG, TM, DB, GA, and GK involved in the data analysis and drafting of the manuscript, gave suggestions on the whole research paper, also were involved in the interpretation of the data, and contributed to manuscript preparation. Similarly, all authors have read and approved the final version of the manuscript.

\section{Acknowledgments}

The authors would like to thank Aksum University, study participants, and data collectors for their contribution in the success of our work. Data collection only was covered by Aksum University.

\section{References}

[1] J. B. Mason, L. S. Saldanha, U. Ramakrishnan et al., "Opportunities for improving maternal nutrition and birth outcomes: synthesis of country experiences," Food and Nutrition Bulletin, vol. 33, no. 2 Suppl, pp. S104-S137, 2012.

[2] F. Ahmed and A. Urooj, "Glucose-lowering, hepatoprotective and hypolipidemic activities of stem bark of Ficus racemosa in streptozotocin-induced diabetic rats," Journal of Young Pharmacists, vol. 1, no. 2, p. 160, 2009.

[3] Z. Salem, F. Ebrahimi, F. Aminzadeh, and Z. Asadolahi, "The prevalence of malnutrition and its association with pregnancy outcome among pregnant women in Rafsanjan, Iran, in 2016," Journal of Occupational Health and Epidemiology, vol. 6, no. 2, pp. 106-113, 2017.

[4] R. L. Bailey, K. P. West Jr., and R. E. Black, "The epidemiology of global micronutrient deficiencies," Annals of Nutrition and Metabolism, vol. 66, no. Suppl 2, pp. 22-33, 2015.

[5] N. M. Nnam, "Improving maternal nutrition for better pregnancy outcomes," Proceedings of the Nutrition Society, vol. 74, no. 4, pp. 454-459, 2015.

[6] M. A. Mendez, C. A. Monteiro, and B. M. Popkin, "Overweight exceeds underweight among women in most developing countries," The American Journal of Clinical Nutrition, vol. 81, no. 3, pp. 714-721, 2005.

[7] M. S. Zahangir, M. M. Hasan, A. Richardson, and S. Tabassum, "Malnutrition and non-communicable diseases among Bangladeshi women: an urban-rural comparison," Nutrition \& Diabetes, vol. 7, no. 3, p. e250, 2017.

[8] H. Yasmin, "Epidemiology of malnutrition: maternal and child malnutrition," Journal of Gynecology and Neonatal Biology, vol. 2, no. 2, pp. 1-5, 2016.

[9] C. V. Kramer and S. Allen, "Malnutrition in developing countries," Paediatrics and Child Health, vol. 25, no. 9, pp. 422-427, 2015.

[10] R. Black, C. Victora, S. Walker et al., "Maternal and child undernutrition and overweight in low-income and middleincome countries," The Lancet, vol. 382, no. 9890, pp. 427-451, 2013.

[11] U. Ramakrishnan, "Nutrition and low birth weight: from research to practice," The American Journal of Clinical Nutrition, vol. 79, no. 1, pp. 17-21, 2004.

[12] M.-T. Ververs, A. Antierens, A. Sackl, N. Staderini, and V. Captier, "Which anthropometric indicators identify a pregnant woman as acutely malnourished and predict adverse 
birth outcomes in the humanitarian context?" PLoS Currents, vol. 5, 2013.

[13] F. Salim and N. Begum, "Nutritional status and knowledge about nutrition during pregnancy among pregnant and postpartum women," Northern International Medical College Journal, vol. 6, no. 2, pp. 61-63, 2015.

[14] M. Endalifer, M. Tewabe, and A. Adar, "Undernutrition and associated factors among pregnant women attending ANC follow up in Alamata general hospital, Northern Region, Ethiopia, 2017," Journal of Nutritional Health \& Food Engineering, vol. 9, no. 3, pp. 70-78, 2019.

[15] H. Kedir, Y. Berhane, and A. Worku, "Magnitude and determinants of malnutrition among pregnant women in eastern Ethiopia: evidence from rural, community-based setting," Maternal \& Child Nutrition, vol. 12, no. 1, pp. 51-63, 2016.

[16] M. Moges, A. Worku, and E. Loha, "Nutritional status and associated factors among pregnant women in Boricha Woreda, Sidama Zone, Southern Ethiopia," European Journal of Nutrition \& Food Safety, vol. 5, no. 5, p. 386, 2015.

[17] A. Adikari, R. Sivakanesan, D. Wijesinghe, and C. Liyanage, "Assessment of nutritional status of pregnant women in a rural area in Sri Lanka," Tropical Agricultural Research, vol. 27, no. 2, pp. 203-211, 2016.

[18] N. Regassa and B. J. Stoecker, "Contextual risk factors for maternal malnutrition in a food-insecure zone in southern Ethiopia," Journal of Biosocial Science, vol. 44, no. 5, pp. 537-548, 2012.

[19] M. Tafa and J. Haidar, "Effect of modern family planning use on nutritional status of women of reproductive age group at Tena District, Arsi Zone, Oromiya Region, Ethiopia: a comparative study," The Ethiopian Journal of Health Development (EJHD), vol. 28, no. 2, 2014.

[20] A. Sonko, "Assessment of dietary practice and anthropometric status of pregnant women in Aleta Chuko Woreda southern Nations, Nationalities and People's region/SNNPR/, Ethiopia," Journal of Epidemiology and Public Health Reviews, vol. 1, no. 1, pp. 1-9, 2016.

[21] S. Abasizadeh, Z. Hemati, and F. Deres, "Prevalence of malnutrition during pregnancy and associated factors in women of Ardal County in 2012-2013," International Journal of Epidemiologic Research, vol. 3, no. 1, pp. 19-25, 2016.

[22] B. Gebre, S. Biadgilign, Z. Taddese, T. Legesse, and M. Letebo, "Determinants of malnutrition among pregnant and lactating women under humanitarian setting in Ethiopia," $\mathrm{BMC} \mathrm{Nu-}$ trition, vol. 4, no. 1, p. 11, 2018.

[23] M. Hajizadeh and S. Nghiem, "Does unwanted pregnancy lead to adverse health and healthcare utilization for mother and child? Evidence from low-and middle-income countries," International Journal of Public Health, vol. 65, no. 4, pp. 457-468, 2020.

[24] M. M. Rahman, "Is unwanted birth associated with child malnutrition in Bangladesh?" International Perspectives on Sexual and Reproductive Health, vol. 41, no. 2, pp. 80-88, 2015.

[25] J. Adinma, O. Umeononihu, and M. Umeh, "Maternal nutrition in Nigeria," Tropical Journal of Obstetrics and Gynaecology, vol. 34, no. 2, pp. 79-84, 2017.

[26] World Health Organization, Nutrition of Women in the Preconception Period, during Pregnancy and the Breastfeeding Period, vol. 13, WHO, Geneva, Switzerland, 2012, Provisional Agenda Item.

[27] M. A. A. Alexandre, S. G. Benzecry, A. M. Siqueira et al., "The association between nutritional status and malaria in children from a rural community in the Amazonian region: a longitudinal study," PLoS Neglected Tropical Diseases, vol. 9, no. 4, 2015.

[28] L. M. Muñoz, B. Lönnerdal, C. L. Keen, and K. G. Dewey, "Coffee consumption as a factor in iron deficiency anemia among pregnant women and their infants in Costa Rica," The American Journal of Clinical Nutrition, vol. 48, no. 3, pp. 645-651, 1988.

[29] J. Olsen, K. Overvad, and G. Frische, "Coffee consumption, birthweight, and reproductive failures," Epidemiology, vol. 2, no. 5, pp. 370-374, 1991.

[30] G. Kumera, K. Haile, N. Abebe, T. Marie, and T. Eshete, "Anemia and its association with coffee consumption and hookworm infection among pregnant women attending antenatal care at Debre Markos Referral Hospital, Northwest Ethiopia," PLoS One, vol. 13, no. 11, 2018.

[31] World Health Organization, Requirements of Vitamin A, Iron, Folate, and Vitamin B12: Report of a Joint FAO/WHO Expert Consultation, Food \& Agriculture Organization, Rome, Italy, 1988.

[32] D. Kuche, P. Singh, D. Moges, and T. Belachew, "Nutritional status and associated factors among pregnant women in Wondo Genet District, Southern Ethiopia," Journal of Food Science and Engineering, vol. 5, pp. 85-94, 2015.

[33] A. Mariyam and B. Dibaba, "Epidemiology of malnutrition among pregnant women and associated factors in central refit valley of Ethiopia, 2016," Journal of Nutritional Disorders and Therapy, vol. 8, no. 1, 2018. 